Research Article

\title{
Online Education Optimization Based on Edge Computing under the COVID-19 Pandemic
}

\author{
Huiling Wang $\mathbb{D}^{1}$ and Jiasheng Wang $\mathbb{D}^{2}$ \\ ${ }^{1}$ Chongqing City Management College, Chongqing 401331, China \\ ${ }^{2}$ Chongqing Electric Power College, Chongqing 400053, China
}

Correspondence should be addressed to Jiasheng Wang; wjscqu@cqu.edu.cn

Received 10 August 2021; Revised 15 September 2021; Accepted 18 October 2021; Published 27 November 2021

Academic Editor: Punit Gupta

Copyright (c) 2021 Huiling Wang and Jiasheng Wang. This is an open access article distributed under the Creative Commons Attribution License, which permits unrestricted use, distribution, and reproduction in any medium, provided the original work is properly cited.

\begin{abstract}
The COVID-19 pandemic has strongly affected education in China, even if education departments and corresponding schools took a series of measures to manage online education of the school's new semester in China, including maneuver, learning platform allocation, and teacher training. In this paper, edge computing is used to optimize online education, and a task offloading algorithm is designed to minimize the computing delay of terminal tasks. Through preparation, practice, and reflection of this online education, this study aims to comprehensively demonstrate the learning condition of online education in China and present the real adjustment impact based on the problems encountered during the process. Although several schools gradually reopened to students in 3 months, several improvements are warranted in various ways. This study proposes the construction of education infrastructure, the adjustment of teaching organization, and the learning methods of teachers and students, providing a clear guiding significance for the development and enhancement of online education in the future.
\end{abstract}

\section{Foreword}

In mid-to-late January 2020, colleges, middle schools, and elementary schools in China were transitioning from the winter vacation when the COVID-19 virus outbreak, with acute infectious characteristics and asymptomatic incubation period, erupted and soon became a pandemic [1]. Based on its experience of handling the SARS pandemic of 2003, the Chinese government soon took a series of countermeasures, such as regulating population movements and decreasing population aggregation, especially in schools [2]. Considering the upcoming new semester, the Ministry of Education proposed an online education model to substitute the traditional face-to-face teaching model for governing the teaching progress under large-scale developed Internet construction in China. Consequently, some time was taken to prepare for the new semester, such as commissioning the teaching platform, persuading teachers and students to use the platform, and tapping and allocating educational resources-all of which are currently proceeding regularly.
During the pandemic, China had 518,800 schools at various levels and types, 16.673 million full-time teachers, and 276 million students. It was unprecedented for the education system to conduct large-scale, nationwide online education for hundreds of millions of students during the pandemic prevention and control period.

Online education paves a new way of life, work, and learning across time and space by applying information and Internet technology. Thus, the way of knowledge acquisition has endured a fundamental alteration [2]. Indeed, in October 2019, the Ministry of Education of China, along with 11 departments, jointly proposed that the infrastructure construction level of online education would be markedly enhanced by 2020; modern information technology, such as the Internet, big data, and artificial intelligence, will be more extensively used in the education field, and the online education model will be rendered more extensively perfect, with abundant resources and services [3]. During the COVID-19 pandemic, it is time to accrue experience for this education reform, which is an opportunity to further augment the quality and depth of online education. 
After the lockdown of Wuhan City on January 23, 2020, Chongqing Municipal Education Commission and several colleges and universities adopted a predictive management model and established an "emergency leadership group" to handle the upcoming large-scale development of online education. During the winter vacation and the Chinese Spring Festival, the schools' management staff communicated with students and their parents in advance and introduced them to what might occur in the teaching mode after the holiday. During the COVID-19 pandemic, China's Internet reached an equitably mature and stable stage, and several conditions of online education, such as teaching platforms, microclasses, and teaching resources, were relatively adequate. Besides, this pandemic proved to be the best test of all aspects, providing sound guidance and inspiration for online education in the future.

\section{Online Education Foundation and Higher Education in China}

2.1. Online Education: A Crucial Supplement to Education. With the advancement of information technology, online education preserves a stable development trend around the globe. Online education originated in the United States. Almost all top American colleges and universities have already launched online education. The majority of colleges and universities consider online education as a long-term development strategy. In addition, over half of the colleges and universities provide online degrees, all of which have become an integral part of the education system. With the assistance of the online platform independently developed by universities, the online education system in the United States has garnered numerous learners from all over the world $[4,5]$. Of note, the online education objective is open to the world and crosses the social, family, economic, time, space, physiological, and other impediments. Thus, it can relax educational inequality in China, which comprises a large population and regional development differences. In recent years, the State Education Commission of China has guided and endorsed online education development, making it a vital part of the education system. Consequently, it has made remarkable successes as shown in Figure 1. A study reported that the online education market in China would reach 387 billion yuan in 2019 and 433 billion yuan in 2020 [6].

2.2. Premanagement and Countermeasures of Online Education. Based on the response experience accrued during the SARS outbreak in China, several education departments did corresponding research and decided to prioritize online office and conference, thereby progressively introducing "online education." Meanwhile, based on the situation during the pandemic, various large education platforms, such as New Oriental and Tomorrow Advancing Life (TAL), have taught lessons through online education. First, the regular management procedure and the implementation of teaching affairs, such as meetings and program operations, will be executed by the Internet, and project application is paperless through the Internet. As a supplement, full-time personnel are hired on duty for specific major projects, which warrant actual participation. Second, the teaching departments launched multiple online projects such as microclass production, online education, and high-quality e-textbooks before the pandemic. However, the coverage of all courses and involvement of all students in China and online education, which will replace the traditional one, were not considered. Third, considering the large scale of students in China, the education committees and schools at all levels explored several online education platforms, including TAL, massive open online courses of China Universities (MOOC), teaching cloud platform, and intelligent vocational education. Consequently, they promoted an online platform of open courses of Chongqing universities, experimental space (National simulation platform). Simultaneously, numerous corresponding teaching platforms are available such as Tencent Classroom and Tencent learning group for backup. Finally, some professionals were recruited to appease students and their parents in mental health care.

2.3. Requirements of Online Education and Adjustment Mechanism. Roger [7] reported that the adaptability of innovation in an organization depends on the following three factors: (i) the relevant features of organizational members; (ii) the innovation itself; and (iii) the pertinent information dissemination. Based on the analysis provided above, teaching in China has conditions of large-scale online education. First, the Internet has undergone significant progress in China, and there exist numerous large local multinational enterprises, such as Huawei, Zhongxing Telecom Equipment, and Tencent, since 2000. Currently, China has advanced information technology and Internet speed. Second, China's online education has also exhibited significant progress after 20-year development and has become a significant supplement of the education system gradually; indeed, the teaching impact of some courses can reach or even exceed the traditional teaching model. Finally, China has a broad base of Internet users, and the network has become one of the most crucial media in the country. Besides, it has already had the full use of the network to disseminate information and corresponding teaching conditions. Thus, large-scale online education offered fundamental support in China, and the COVID-19 pandemic also provided an opportunity to promote and perfect it. In the atypical period, the Internet helped us realize the preaching, receiving employment, and addressing queries between teachers and students.

\section{Practice, Adjustment, and Impact of Large- Scale Online Education}

After the beginning of the new semester, educational administration and teaching were processed online, and the corresponding teaching model was adjusted and perfected in practice. 


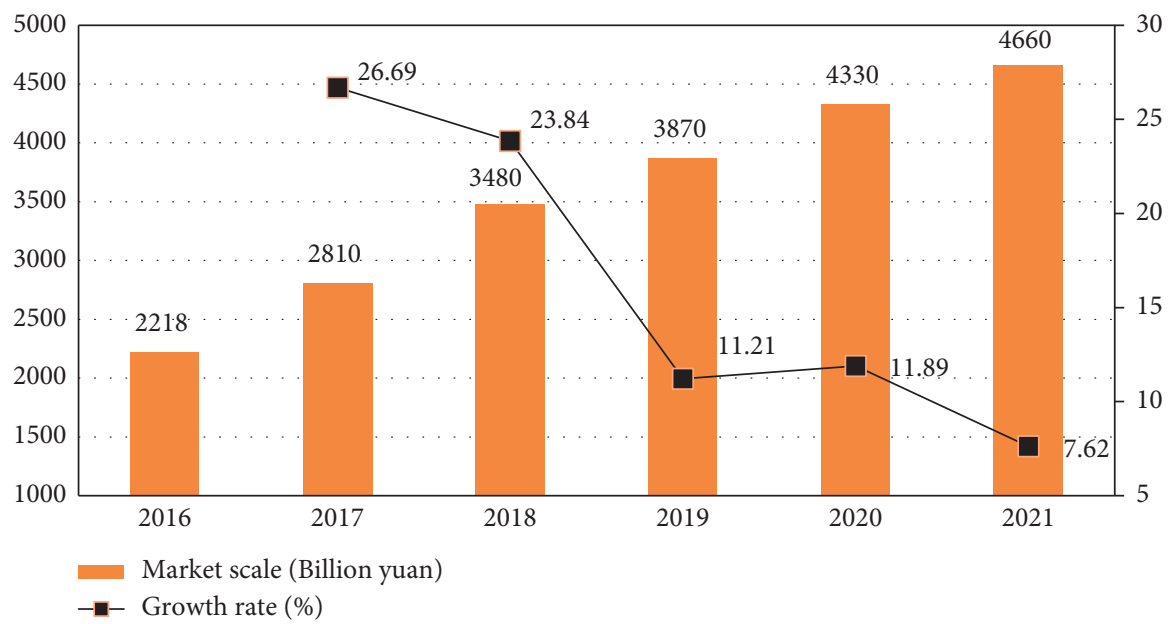

Figure 1: The 2016-2021 China online education market scale and forecast. Note: the data were obtained from Ref. [5], and the data were collected in 2019.

3.1. The High Efficiency of Teaching Administration. With the high-speed Internet access, the efficiency of school conference management improved markedly, the participation rate of the meeting was high, and the cost was significantly reduced; timeliness of information transmission was significantly improved and guaranteed; without time and space constraints, the school meeting was notified 1 hour in advance, and the participants could be in place during the COVID-19 pandemic. Fortunately, a relatively stable network exists in China, including mobile, telecommunications, and cable TV networks. Typically, teachers can enter a meeting as soon as possible, and the meeting time is also relatively short. During the pandemic, more emergency meetings were commenced in schools, which were relatively timely and reliable. Conversely, there were more school administrative meetings and academic meetings in the non-pandemic period. If the organizers could optimize the conference configuration and select the appropriate meeting by the Internet, the work efficiency of teachers and students would be significantly enhanced.

During the pandemic, many universities launched largescale online job fairs, where candidates could complete the interview online. For example, Tsinghua University, Harbin University of Technology, Chongqing University, and other universities took the remote defense mode for numerous doctoral candidates. Some international competitions, such as the finals of the 2020 Future Problem Solving Program International Chinese National Competition, were also launched online on March 28, and the team members attained the goal through Tencent Meeting and completed the competition content. Although there is no close contact, the students can still feel that this is a game. Furthermore, some elementary school students created study groups online to jointly complete the homework assigned by teachers.

\subsection{Miscellaneous Platforms and Mismatched Teaching} Resources. In the last few years, several multinational enterprises have materialized online office, and the number of people working remotely online has risen dramatically. During the COVID-19 pandemic, the number of telecommuting personnel surged, which led to some congestion in the network. Thus, when all students participate in online learning, network congestion is inevitable. Although the education department conducted various tests during the winter vacation, the teachers performed well in advance. After the semester began, on February 17, 2020, universities, middle school, and primary schools started classes in stages, and students took online classes by the public online platform. Nevertheless, several online education platforms collapsed, such as MOOC, teaching cloud platform, and intelligent vocational education, and live teaching of most courses failed because of severe network congestion. To handle such problems, the education department arranged classes in more detailed stages and decentralized network traffic; nonetheless, network congestion prevails. Consequently, many teachers and students selected the selfmedia platform Tencent to complete teaching.

Meanwhile, the education department and school teachers prudently prepared and contacted some public online platforms, which then actively responded. However, some schools and teachers did not keep their promise and refused to provide public resources with multiple excuses during the policy implementation. Likewise, jamming during Internet traffic peak is standard on many public online platforms in China. Hence, most teachers and students selected the Tencent platform. However, online platforms, such as TAL and VIPKID, which are charging platforms, were relatively smooth, highlighting deficient technical handling and management of several public platforms. Usually, some private or charging platforms were worried about losing their customers, and they appeased users from management and commercial communication and augmented their technology to make their platforms smooth. During the adjustment process, the private and charging platforms added class interaction and function module, making the platforms more attractive and effective. Finally, teachers of public online platforms, such as MOOC, vocational education cloud, and cloud platform, selected the Tencent platform.

In the first large-scale online education, teaching software, network facilities, computer equipment, and other 
hardware differed from teachers and students, causing differences in teachers' proficiency and also affecting the class quality. Meanwhile, students varied from regions and family backgrounds, for example, some students in rural areas had low network signal, and they often disconnected during live teaching, while some students even had no computer at home.

\subsection{Less Interactive Support and Low Concentration in Class.} As a large number of participants in online education came from different family backgrounds, many had different perspectives toward online education. Indeed, some students even had no essential concept, let alone listening to online classes. Through the census, several rural students were relatively poor in teaching resources and had no progress management in classes. In the real process, several students did not wholly participate in online education and complete homework. Hence, numerous schools prompted students to return to classrooms as soon as possible and rearranged the process test. For the first large-scale online education, the educated group itself had a broad range, and it was challenging for teachers to monitor or supervise the process entirely, especially for imperfect platform modal and learning condition. Meanwhile, requiring an enhancement in teaching quality was unrealistic too.

Certainly, the growing age of students is clearly defined. For example, elementary school students are relatively weak in self-discipline and get easily distracted; thus, they need to be more restrained in class. Middle school students have higher relative self-control ability; however, they need to be reminded or interacted in some places. College students, on the other hand, are basically self-study based on purpose. All these warrant educators to study individual characteristics judiciously. At the beginning of online education, several students listened more intensively; however, with time, students became bored with such education. In teaching, if no interaction occurs between teachers and classmates, students tend to lose interest and become inattentive gradually. Students who want to learn will promote their progress through continuous interaction, whereas those who do not want to learn will often choose games to escape, and the impact of online learning would decline significantly over time.

3.4. Low Recognition of Online Education Quality. Owing to varying teaching conditions, the type of teaching organization will also change; after all, it is the bridge between teaching and learning and will reorganize and arrange teaching activities based on the teaching specific ideas, goals, content, and subjective and objective conditions [8]. There exists a complete lack of essential exploration and experimentation in the teaching organization for the abruptness of the pandemic outbreak. It is highly challenging for teachers to break the limitation in time and space and effectively combine the enormous contrast between online education and the traditional model; this change warrants very high personal organization and the learning ability of teachers. If a teacher is in a hurry to adjust teaching, the adjustment of teaching methods commands high requirements for students. After all, different children's family backgrounds and educational methods ascertain different understanding, and understanding bias can be eliminated only by face-to-face interaction. In the absence of objective conditions (language and behavior), online education lacks communication and integration, inevitably leading to the disapproval of teaching quality.

The typical online education is targeted at students, and its teaching organization has been optimized for a small student range in the online charging platform. With time, the scale of online education proliferates, and its teaching organization cannot be enhanced in a short time; thus, its online class quality is hard to fulfill the expected requirements. Online education quality is the fundamental condition for the continued existence and development of emerging online education. The focus of this research is how to ensure and enhance the quality of online education. In China, for example, the quality of several teaching materials is low, and even the knowledge in the teaching materials is misleading. All these problems need teachers to explain in class.

\section{Enlightenment of Online Education Practice}

Against the backdrop of China's fight against the COVID-19 pandemic, education departments have gone all out and attained certain teaching results; however, online education still needs significant enhancements.

\subsection{Resource Support and Deployment}

4.1.1. Online Education Foundation: Facility Construction. Online education is an integral $\operatorname{cog}$ in the construction of fundamental Internet. As of June 2019, the number of Internet users in China reached 854 million, the Internet penetration rate was $61.2 \%$, and the number of broadband access users $>100$ million, accounting for $77.1 \%$ of the total Internet access [9]. Thus, China's high-speed Internet has not been wholly popularized yet. For regions where the Internet has not yet been connected to broadband or the capacity is inadequate, regular online education is affected markedly. Besides the interruption of video and live broadcasts, net jams also occur in cities, and many students are even squeezed out during class. On the other hand, several technical and management issues warrant improvement. Although the Tencent platform also experienced net jamming at the beginning of the new semester, the jam gradually vanished, and even many interaction models were added to enhance the platform after continuous optimization and improvement. Consequently, several teachers and students finally flocked to Tencent. The change is also vividly reflected in the charging platform TAL. Initially, TAL was blocked; however, its technicians adopted switching lines for winning time and optimized its platform until the jam was eliminated. Besides, the improved platform is more interactive between teachers and students. Hence, TAL not only retains its original customers but also attracts some customers from other platforms. Conversely, some charging 
platforms lack technology and creativity owing to the loss of customers during the pandemic.

Based on the students' characteristics in the region, the education departments will establish a corresponding platform for the corresponding student groups. The enhancement of the education platform also should be upgraded after the network technology matures. If the platform advances quickly, it increases the requirements for users and facilities. Besides, it can increase technical maintenance, which is also a crucial part; it can gather the platform information in real time, optimize the platform environment, and assist with the administration when necessary. During the COVID-19 pandemic, Facebook decreased the clarity of its software images to reduce network traffic, enabling people who need it more to use the Internet. Likewise, China also adopted measures like staggered surfing, effectively alleviating net jamming.

\subsubsection{Enrichment and Enhancement of Educational} Resources. In primary and secondary schools, uniform textbooks are present in China, and the relative error rate is low. However, many university textbooks are recommended by teachers. Due to the lack of supervision, the quality of these books is relatively low and often cannot meet the teaching requirements [10]. Currently, to seize the teaching textbook market, several publishing houses let textbooks go unsupervised, resulting in low quality. Second, some publishing houses did not open their textbooks to students during the pandemic, and some students had no textbooks in class. In traditional classrooms, teachers can correct errors in textbooks by direct communication; it is hard to deal with such problems in online education; at least, it would take some time to find suitable methods to perfect it. If online education is to be promoted on a large scale, textbook and teachers' quality should be improved markedly.

In April, after several students returned to school in China, even more students took online classes on the charging platform than before the outbreak. First, the habit of students taking online classes was shaping gradually. Second, the platforms ensured the improvement of teaching quality; their teachers graduated from famous universities at home and abroad, such as Zhejiang University and Peking University, besides excellent textbooks compiled by the platform teachers. Finally, good management was essential; over tens of thousands of students were studying in a TAL class, and these students were divided into many small classes to complete their homework, all of which was taken care of by some ordinary teachers. Furthermore, the charging was cost-effective for students and teaching quality and recommended books were good.

For large-scale online education, the education department must first reinforce control over the teachers' quality. If a teacher is unqualified, it will harm students [11]. Meanwhile, teaching textbook quality must be enhanced; after all, learning in class only is transient, and reinforcement and upgrading based on textbooks after class is the most crucial part [12]. Although China's education department has undertaken the construction of several planning teaching materials, excellent resource sharing courses, majors, and national teaching achievement awards, the actual impact has not reached a high level in terms of operability and quality at all.

\subsection{Changing Participants' Attitude toward Online Education.} At the beginning of the pandemic, online education was not accepted by most Chinese people because of long-time dominated traditional offline education. Compared with traditional education, online education has demonstrated its advantages during the pandemic to everyone, including students, students' parents, and teachers, which is also extensive marketing for online education. Despite several problems, online education has also played its advantages in several aspects, especially for time and efficiency, and there remains considerable room for improvement. Nowadays, educators and the educated consider more time efficiency in an era of knowledge explosion and fierce competition. Traditional education is a systematic framework; however, online education can replace these educational methods and fulfill the requirements of parents and students themselves. This is also the charm of the tremendous progress of online education at home and abroad in recent years. Likewise, several charging online platforms provide various online public classes such as Chinese, mathematics, physics, chemistry, and so on. Besides, these platforms provide excellent textbooks, teachers, and cheap fees for students.

Of note, the development of online education is inevitable. Thus, teachers and parents must harness their ability in online education and knowledge appraisal as well as guide students to effectively use online resources to enhance learning efficiency [13]. After the pandemic, the ability training of online education would become a major area. The online application can be indorsed in primary and secondary schools early and can implant professional classes; the requirement can augment the integration of students and teachers in advance. It is imperative to guide students to use the Internet to obtain resources correctly and effectively [14]. Second, parents should have a correct attitude toward online education, and they must be capable of identifying its advantages and disadvantages. Under such a situation, parents can exercise supervision and guide children's learning effectively at home. After all, online education is a live broadcast and open to the public; the fundamental application skills of online education and the preparation of professional courses are more demanding for a teacher.

\subsection{The Application of Information Technology as an Edu-} cational Tool. Previously, schools and parents in China kept students away from computers and mobile phones to prevent them from playing games. The pandemic has also made schools and parents realize the significance of information technology courses and online education. Based on the effect of online education in the pandemic, the education department can implant more information technology courses into standard teaching in advance [15]. Meanwhile, it is also feasible to augment regular management and educational activities through the Internet. Of note, the security of the 
campus Internet must be strengthened; however, ordinary meetings can be adopted online, which is not suitable for large-scale work meetings involving confidentiality. If one intends to open a meeting in this area, you can use the internal lines of the campus network.

In addition, the operation of online education has highlighted several problems during the pandemic. First, students and teachers did not adapt to online education. Teachers were nervous or helpless in class, while students had relatively weak Internet knowledge. For students of colleges or universities, student's backgrounds differed, and their adaptability to online education varied markedly. The answer to this problem lies in unhinged education development. Thus, the online education department can standardize the frequently used functional modules and promote it in schools at all levels. Likewise, introducing some interactive links can be implanted in a public platform, such as group discussion and answering, which would assist students and teachers at all levels to provide online education purposefully. Besides, it is feasible to develop a self-grading platform for students, such as embedded algorithms like roll call, sign-in, interactive question answering, and homework, which can automatically serve as the general evaluation and can effectively decrease the teachers' workload. In preventing net jamming, an optimized algorithm can be used, or an optimized guarantee strategy can be adopted at the beginning of construction.

4.4. Teaching Management and Quality Improvement. Students, parents, and teachers had a difficult adjustment section toward online education because the teaching methods and habits of online education differed significantly from traditional education. Despite having reservations about the quality of education during the pandemic, participants and guardians only had this one option to choose from. Nonetheless, learning efficiency has always been a primary concern of online education practitioners. As an upcoming teaching mode, the form of online teaching organization should be changed considerably to enhance its efficiency.

In the traditional offline classes in China, teachers are the mainstay, and students are supplementary, whereas the essential positioning of the teacher-student role in online education is "learner-centered." Teachers are more often "assistants," the builders of "scaffolding" in the growth of students' thinking and innovation ability. In addition, curriculum design is a major concern, such as how to prevent students from distracting themselves or loss of vision during online class; all these can be effectively evaded through teaching organization. Regarding curriculum design, no matter how good online education is, several students still cannot achieve perfect communication. The new teaching organization will make students participate in the class as fully as possible and learn independently. From this perspective, the pandemic has provided more people with new thinking about online education; perhaps, China's forms of education would also become diversified in the future.

The curriculum can be created in different levels by the characteristics of students (e.g., primary school, junior high school, high school, and university) and the course itself.
Unquestionably, it also can be the principle of combining online and offline education; part of the theory is taught online, while the offline part mostly focuses on practical. From the standpoint of large-scale teaching, there are tens of thousands or even hundreds of thousands of students (basic mathematics or Chinese) in an online class (TAL net class or some famous scholars' class), whereas teachers can teach one-to-one online or offline for challenging courses.

A general survey of online education revealed that students' learning effect is not good. Encountering the everincreasing number of online courses, how to construct a comprehensive, objective, and instructive quality evaluation system is a pressing problem in China, which can not only give full play to the traditional advantages of China's education and teaching but also promote the benign development of large-scale online education courses in China.

\section{Conclusions}

The development and optimization of online education in China is an inevitable trend with the development of network technology. In addition, the pandemic offered an excellent opportunity for the education department to optimize online education continuously in practice. For instance, the quality of textbooks, teaching organization forms, and several specialized reforms are on the road for teachers and students, whereas China's 5G network is built, and public platforms are also optimized.

Moreover, parents and students can now fully realize the advantages of online education after experiencing the initial maladjustment of the pandemic. Even after the schools reopened, many students still opted for online education in many classes; this is the driving force of substantial growth in online students after the schools reopened compared with before the pandemic.

Furthermore, the online education platforms seized the catalyst of the "pandemic" to constantly innovate and tap their potential, which also won the trust of their customers. Besides, parents and children also affirmed this online education model during this period. Going forward, the map of the education industry will be reshuffled in the future, and online education will change from a supplementary method of traditional teaching to a mainstream method.

\section{Data Availability}

No data were used to support this study.

\section{Conflicts of Interest}

The authors declare that they have no conflicts of interest.

\section{Acknowledgments}

This study was supported by the Special Research Project of One Belt, One Road Education International Cooperation in 2019 (no. 19YDYL10), Chongqing Education Planning Project (no. 2020-GX-384), and Research Project of Chongqing City Management College (no. B-2). 


\section{References}

[1] Y. Pan, D. Zhang, P. Yang, L. M. P. Leo, and Q. Wang, "Viral load of sars-cov-2 in clinical samples," The Lancet Infectious Diseases, vol. 20, no. 4, 2020.

[2] C. Chen, X. Zhu, and L. I. Xueru, "Campus management in the crisis of SARS," Higher Education Exploration, no. 2, pp. 2-8, 2020, (in Chinese).

[3] xinhuanet, "The level of infrastructure construction for online education will be greatly improve in China," 2019, http://www.xinhuanet.com/politics/2019-10/02/c_ 1125068451.htm(in Chinese).

[4] Y. H. Zhu, X. B. Han, J. Yang, and J. G. Cheng, "Irreversible online development of higher education:systematic analysis of 11-year sloan consortium report series on online education in the US," Tsinghua Journal of Education, no. 4, pp. 92-100, 2014, (in Chinese).

[5] I. Consultation, "China's Online Education Market Will Reach 387 Billion Yuan in 2019,” 2019, https://www.iimedia. $\mathrm{cn} / \mathrm{c} 1061 / 65338 . \mathrm{html}$.

[6] L. Peng and L. Zhou, "Reflections on the quality of online education by consulting," JOURNAL OF HIGHER EDUCATION RESEARCH, vol. 29, no. 3, pp. 66-68, 2006, (in Chinese).

[7] M. D. Byrd, "Back to the future for higher education," The Internet and Higher Education, vol. 4, no. 1, pp. 1-7, 2001.

[8] M. A. Xiaoqiang and D. U. Liping, "The evolution of organizational form of instruction and network-based teaching [J]," Educational Research, vol. 23, no. 4, pp. 49-51, 2002, (in Chinese).

[9] China Internet Network Information Center, "The 44th statistical report on China's Internet development," 2019, http://www.cac.gov.cn/2019-08/30/c_1124938750.htm(In Chinese).

[10] Z. Chen, "Research on online education development strategy of publishing industry under the concept of teaching resource sharing," China Publishing Journal, no. 12, pp. 29-32, 2017.

[11] X. Yang and X. Zhou, "Research on current situation and development trend of online education in China: from analysis of NetEase open class and other 16 online education platforms," E-education Research, vol. 38, no. 8, pp. 63-69, 2017, (in Chinese).

[12] J. Shen, "Challenges, problems and trends of textbook construction in the new era," Curriculum, Teaching Material and Method, no. 9, pp. 7-9, 2019, (in Chinese).

[13] L. Wang, "The Lates t development of MOOCs in the USA and its implications to Chinese higher education: based on an interpretation of sloan report series," Journal for Higher Education Management, no. 5, pp. 34-40, 2014, (in Chinese).

[14] J. Yang, "Science teaching focuses on guiding students to explore independently," China Educational Technique \& Equipment, no. 13, 2011.

[15] Q. Yang and Y. U. Liang, "Analysis of the connotation, characteristics and core elements of "internet + education"," The Chinese Journal of Ict in Education, no. 3, pp. 25-30, 2018, (in Chinese). 